\title{
Low-Cost Graphite on Paper Pressure Sensor for a Robot Gripper with a Trivial Fabrication Process
}

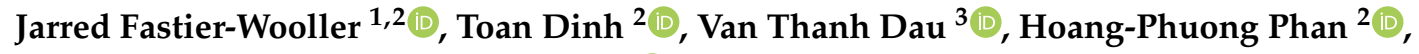 \\ Fuwen Yang ${ }^{1}$ and Dzung Viet Dao ${ }^{1,2, *(D)}$ \\ 1 Griffith School of Engineering and Built Environment, Griffith University, Gold Coast, QLD 4222, Australia; \\ jarred.fastier-wooller@griffithuni.edu.au (J.F.-W.); fuwen.yang@griffith.edu.au (F.Y.) \\ 2 Queensland Micro- and Nanotechnology Centre, Griffith University, Brisbane, QLD 4111, Australia; \\ toan.dinh@griffithuni.edu.au (T.D.); hoangphuong.phan@griffithuni.edu.au (H.-P.P.) \\ 3 Research Group of Environmental Health, Sumitomo Chemical Ltd., Hyogo 665-8555, Japan; \\ dauthanhvan@gmail.com \\ * Correspondence: d.dao@griffith.edu.au; Tel.: +61-755-527-515
}

Received: 15 June 2018; Accepted: 28 September 2018; Published: 1 October 2018

check for updates

\begin{abstract}
A flexible pressure sensor with a rudimentary, ultra-low cost, and solvent-free fabrication process is presented in this paper. The sensor has a graphite-on-paper stacked paper structure, which deforms and restores its shape when pressure is applied and released, showing an exceptionally fast response and relaxation time of $\approx 0.4 \mathrm{~ms}$ with a sensitivity of $-5 \% / \mathrm{Pa}$. Repeatability of the sensor over 1000 cycles indicates an excellent long-term stability. The sensor demonstrated fast and reliable human touch interface, and successfully integrated into a robot gripper to detect grasping forces, showing high promise for use in robotics, human interface, and touch devices.
\end{abstract}

Keywords: graphite on paper; paper switch; resistive pressure sensor

\section{Introduction}

Developing flexible and high sensitivity sensors for robot hands is of interest for accomplishing a wide range of tasks such as object manipulation, articulation, and gesture activities. The requirements for these sensors include but are not limited to (1) high sensitivity and a wide measurement range, (2) fast response and excellent repeatability, (3) soft flexibility and stretchability, and biodegradability, (4) low cost and simplicity for implementation/integration into robot hands. These sensors can range from simple two-state switches to high precision pressure/tactile sensors [1-5]. For example, several studies have successfully demonstrated tactile sensors with the capability of both operating in a tactile and proximity mode for tracking object motion and high-speed hands [6,7].

The working principle of tactile/pressure sensors is typically based on piezoresistive, resistivity, and capacitive effects [8-11]. The recent development of these sensors is summarised in Table 1. Apart from robot hand applications, these sensors have been applied in power switches, keypads/keyboards, touchscreens, weight scales, pressure control/feedback systems, etc. Scientific investigations have been performed on various alternatives to improve and diversify these methods to provide high performance, yet low-cost alternative sensors. Sensor fabrication can include many expensive/advanced materials, such as carbon nanotube/graphene, and complicated procedures/processes that involve cleanroom facilities and toxic chemicals, as seen in Table 1 . The devices described in this table are ordered by the sensing principle to allow for a more relevant comparison. 
Table 1. Performance of pressure sensors in literature.

\begin{tabular}{|c|c|c|c|c|c|c|c|}
\hline Pressure Sensor & Materials & $\begin{array}{c}\text { Design and } \\
\text { Implementation } \\
\text { Cost }\end{array}$ & Sensitivity & Range & Response/Relaxation & Solvent & Ref. \\
\hline Capacitive & $\begin{array}{l}\text { sparkling graphene } \\
\text { block }\end{array}$ & $\begin{array}{l}\text { automatic egg beater, } \\
\text { freeze dry, annealing }\end{array}$ & $\begin{array}{l}229.8 \mathrm{kPa}^{-1} \\
26.86 \mathrm{kPa}^{-1}\end{array}$ & $\begin{array}{l}0-0.12 \mathrm{kPa} \\
0.4-1.0 \mathrm{kPa}\end{array}$ & $\begin{array}{c}\approx 1085 \mathrm{~mm} \mathrm{~s}^{-1} \\
\text { "recovery speed" }\end{array}$ & Yes & [2] \\
\hline Capacitive & $\begin{array}{c}\text { SBS AgNP } \\
\text { Composite-coated } \\
\text { Kevlar Fibre }\end{array}$ & $\begin{array}{l}\text { SBS coating, Ag } \\
\text { precursor absorption, } \\
\text { precursor reduction }\end{array}$ & $\begin{array}{l}0.210 \mathrm{kPa}^{-1} \\
0.064 \mathrm{kPa}^{-1}\end{array}$ & $\begin{array}{l}<2 \mathrm{kPa} \\
>2 \mathrm{kPa}\end{array}$ & $\begin{array}{l}\approx 40 \mathrm{~ms} \\
\approx 10 \mathrm{~ms}\end{array}$ & Yes & [6] \\
\hline Capacitive & $\begin{array}{c}\text { Au-electroplated } \\
\text { planar coil. Si/glass } \\
\text { substrates }\end{array}$ & $\begin{array}{l}\text { dissolved-wafer } \\
\text { process }\end{array}$ & $\begin{array}{c}1580 \\
\mathrm{ppm} / \mathrm{mmHg}\end{array}$ & $0-50 \mathrm{mmHg}$ & $120 \mathrm{kHz} / \mathrm{mmHg}$ & Yes & [12] \\
\hline Capacitive & $\begin{array}{l}\text { MG/PU composite } \\
\text { film }\end{array}$ & $\begin{array}{l}\text { solution } \\
\text { compounding } \\
\text { method }\end{array}$ & $0.274 \mathrm{kPa}^{-1}$ & $0-0.2 \mathrm{kPa}$ & - & Yes & [13] \\
\hline Capacitive & $\begin{array}{c}\text { PDMS coated } \\
\text { graphite on paper }\end{array}$ & paper, pencil, PDMS & $0.62 \mathrm{kPa}^{-1}$ & $<2 \mathrm{kPa}$ & $\begin{array}{l}200 \mathrm{~ms} \text { rise } \\
400 \mathrm{~ms} \text { fall }\end{array}$ & Yes & [14] \\
\hline Capacitive & $\begin{array}{l}\text { PDMS, CPDMS, } \\
\text { Ecoflex }\end{array}$ & $\begin{array}{l}\text { photolithography, } \\
\text { micro-contact } \\
\text { printing, spin-coating, } \\
\text { thermal curing }\end{array}$ & $0.42 \mathrm{~Pa}^{-1}$ & $0-1.2 \mathrm{mPa}$ & - & Yes & [15] \\
\hline Capacitive & $\begin{array}{l}\text { Au nanowire coated } \\
\text { tissue paper, PDMS }\end{array}$ & $\begin{array}{l}\text { dip coating/drying, } \\
\text { PDMS, PDMS } \\
\text { patterned with } \\
\text { integrated electrodes }\end{array}$ & $1.14 \mathrm{kPa}^{-1}$ & $5 \mathrm{kPa}$ & $<17 \mathrm{~ms}$ & Yes & [16] \\
\hline Piezo-resistive & graphene & $\begin{array}{l}\text { CVD sputtering } \\
\text { system }\end{array}$ & $\begin{array}{l}-0.24 \mathrm{kPa}^{-1} \\
0.039 \mathrm{kPa}^{-1}\end{array}$ & $\begin{array}{l}0.3-200 \mathrm{~Pa} \\
700+\mathrm{Pa}\end{array}$ & $>40 \mathrm{~ms}$ & Yes & [1] \\
\hline Piezo-resistive & $\mathrm{Au@PU}$ & ion sputtering & $0.059 \mathrm{kPa}^{-1}$ & $0-5 \mathrm{kPa}$ & $9 \mathrm{~ms}$ & No & [17] \\
\hline Piezo-resistive & $\begin{array}{c}\text { sponge@CNTs@Ag } \\
\text { NPs }\end{array}$ & $\begin{array}{l}\text { "dip and dry" } \\
\text { technique }\end{array}$ & $\begin{array}{l}2.12 \mathrm{kPa}^{-1} \\
9.08 \mathrm{kPa}^{-1}\end{array}$ & $\begin{array}{c}2.24-11 \mathrm{kPa} \\
11-61.81 \mathrm{kPa}\end{array}$ & - & Yes & [18] \\
\hline Piezo-resistive & CB@PU sponges & $\begin{array}{l}\text { water-based LBL } \\
\text { assembly }\end{array}$ & $\begin{array}{l}0.068 \mathrm{kPa}^{-1} \\
0.023 \mathrm{kPa}^{-1} \\
0.036 \mathrm{kPa}^{-1}\end{array}$ & $\begin{array}{c}\approx 0-2.3 \mathrm{kPa} \\
2.3-\approx 10 \mathrm{kPa} \\
\approx 10-\approx 16 \mathrm{kPa}\end{array}$ & $<20 \mathrm{~ms}$ & Yes & [19] \\
\hline Resistive & $\begin{array}{l}\text { VACNT/PDMS } \\
\text { composite }\end{array}$ & $\begin{array}{c}\text { CNT (T-CVD) } \\
\text { sandblasting, etc. }\end{array}$ & $\begin{array}{c}0.3 \mathrm{kPa}^{-1} \\
\sim 0.05 \mathrm{kPa}^{-1}\end{array}$ & $\begin{array}{l}0-0.7 \mathrm{kPa} \\
0.7-2 \mathrm{kPa}\end{array}$ & $\begin{array}{l}\approx 162 \mathrm{~ms} \\
\approx 108 \mathrm{~ms}\end{array}$ & Yes & [3] \\
\hline Resistive & $\begin{array}{c}\text { Au-patterned } \\
\text { polydimethylsiloxane } \\
\text { membrane }\end{array}$ & $\begin{array}{l}\text { MEMs process (PR, } \\
\text { deposition, etc.) }\end{array}$ & $0.23 \mathrm{kPa}^{-1}$ & $0-6.7 \mathrm{kPa}$ & $\approx 200 \mathrm{~ms}$ & Yes & [20] \\
\hline Resistive & $\begin{array}{l}\text { graphene Porous } \\
\text { Network Structure } \\
\text { and PDMS }\end{array}$ & $\begin{array}{l}\text { PDMS infiltration } \mathrm{Ni} \\
\text { etching }\end{array}$ & $0.09 \mathrm{kPa}^{-1}$ & $<1000 \mathrm{kPa}$ & $\begin{array}{l}\approx 100 \mathrm{~ms} \text { rise } \\
\approx 80 \mathrm{~ms} \text { fall }\end{array}$ & Yes & [21] \\
\hline Resistive & $\begin{array}{l}\text { graphene foam and } \\
\text { PDMS }\end{array}$ & $\begin{array}{l}\text { vacuum-assisted } \\
\text { dip-coating reduction } \\
\text { etching }\end{array}$ & $\begin{array}{l}\approx 0.6 \mathrm{kPa}^{-1} \\
\approx 0.8 \mathrm{kPa}^{-1} \\
60 \mathrm{kPa}^{-1}\end{array}$ & $\begin{array}{c}0-200 \mathrm{kPa} \\
200-500 \mathrm{kPa} \\
500+\mathrm{kPa}\end{array}$ & $>10 \mathrm{~s}$ & Yes & [22] \\
\hline Resistive & $\begin{array}{l}\text { graphene-wrapped } \\
\text { PU sponges }\end{array}$ & $\begin{array}{l}\text { RGO-PUS-HT-P } \\
\text { sponge }\end{array}$ & - & $9+\mathrm{Pa}$ & - & Yes & [23] \\
\hline Resistive & $\begin{array}{c}\text { elastic } \\
\text { microstructured } \\
\text { conducting polymer }\end{array}$ & - & $\begin{aligned} \approx & 7.7-41.9 \mathrm{kPa}^{-1} \\
& <0.4 \mathrm{kPa}^{-1}\end{aligned}$ & $\begin{array}{l}<100 \mathrm{~Pa} \\
>1 \mathrm{kPa}\end{array}$ & $\approx 50 \mathrm{~ms}$ & Yes & [24] \\
\hline Resistive & CNT/polymer & $\begin{array}{l}\text { Chemical vapour } \\
\text { deposition, } \\
\text { polymer tape }\end{array}$ & $0.15-0.67 \mathrm{~Pa}^{-1}$ & $0-60 \mathrm{kPa}$ & $100 \mathrm{~ms}$ & Yes & [25] \\
\hline Resistive & graphite on paper & $\begin{array}{l}\text { Paper, Pencil, } \\
\text { office tape }\end{array}$ & $\begin{array}{l}\approx-0.35 \mathrm{~Pa}^{-1} \\
\approx-0.05 \mathrm{~Pa}^{-1}\end{array}$ & $\begin{array}{l}100-250 \mathrm{kPa} \\
300-800 \mathrm{kPa}\end{array}$ & $\approx 0.4 \mathrm{~ms}$ & No & This \\
\hline
\end{tabular}

Environmental issues have been brought to attention, causing a growing interest in the need to develop eco-friendly and biodegradable sensors, for a wide range of applications, including robotics and flexible electronic devices. Paper-based sensory devices have been paid a great deal of attention, owing to their low cost, robustness, biodegradability, and flexibility. More specifically, Graphite-on-Paper (GoP) devices, capable of alleviating many complex fabrication processes, by substituting them with simple pencil drawn structures on a paper substrate, are of high interest for flexible electronic applications. These GoP devices have been successfully investigated in terms of resistors [26], capacitors [27], field effect transistor [28], and chemiresistors for both physical and chemical sensors [29]. Since piezoresistive/resistive pressure sensors have certain advantages in terms of design simplicity, fabrication, and characterisation, GoP resistive pressure sensors could provide further insights into the development of ultra-low cost smart robotics [28,30,31].

In the current work, we present the design, fabrication, and characterisation of a novel ultra-low cost GoP resistive pressure sensor with a very simple fabrication method. The sensor showed an 
exceptionally fast response time compared to that of other literature of $0.4 \mathrm{~ms}$, with excellent long-term stability, after a thousand cycles of testing. Our sensor has a much faster response time, which is at least one order of magnitude faster than that of other pressure sensors, Table 1. In addition, while pressure sensors manufactured by classical mixing process have been reported with the occurrence of sensitivity degradation under dynamic loading or highly non-linear response [32-34], our sensors exhibited excellent long-term stability, repeatability, and no damage when overloading. Successful demonstration of the sensor as tactile feedback for both human and robotic applications shows the potential of the sensor as an ultra-low cost rapid prototyping device, requiring no expensive materials or equipment, and no solvents. The performance of our sensor is comparable to that of numerous sensors employing advanced materials, showing that it has potential uses in robot hands and other versatile fields whose facilities have inadequate funding or lack of access to advanced fabrication processes.

\section{Sensor Principle and Design}

Figure 1a,b shows a schematic cross-sectional sketch of the sensor mechanism. Figure 1c shows a 3D surface profiling image of the GoP in which we can see how pinpoint pressure exerted on the paper during the drawing process causes the drawn areas to deform. Both the paper and the graphite areas share a rough surface area, leading to a pressure dependent contact resistance between the graphite-shaded layers. Pressure is applied perpendicular to the sensor, until the paper deforms, allowing the two graphite layers to make contact through the gaps in the mask, seen in Figure $1 \mathrm{~b}$. As pressure increases, the contact area between the graphite layers increases. Increased contact between the graphite layers causes a reduction in the overall resistance between terminals causing an increased measured electrical current.

(a)

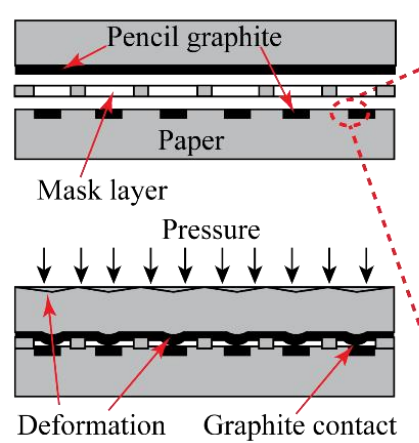

(c)

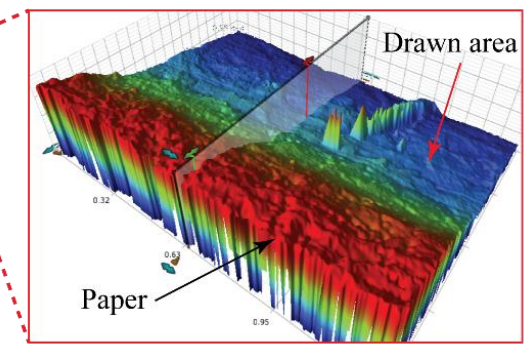

Figure 1. (a) Concept sketch of sensing mechanism with no applied pressure, (b) concept sketch of the sensing mechanism with applied pressure, and (c) 3D surface profile of GoP devices.

A complete and more detailed image of the proposed sensor design can be seen in Figure 2.
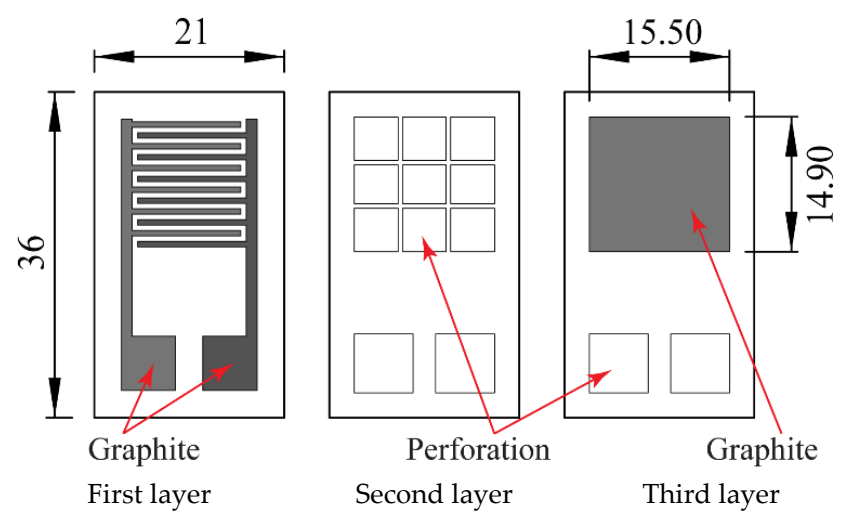

Figure 2. Three main layers of the sensor. 


\section{Fabrication of the Sensor}

The presented sensor is fabricated using elementary and very low-cost methods. The sensor frame is first printed on to a sheet of paper ( 80 gsm Staples A4) using any office or home printing device. The outlined areas for graphite shading are filled-in using a graphite pencil (5B Faber-Castell). Using a scalpel/Stanley knife, the sensor outlines and windows are delicately cut and prepped for assembly. Each layer is aligned and held together with tape (Keji Clear Adhesive). To provide a more elastic sensing surface, a $500 \mu \mathrm{m}$ thick acrylic elastomer layer (3M VHB Acrylic Foam Tape) can be adhered to the sensing area of the sensor, as seen in Figure 3, to provide a softer interface (ergonomic feedback) when pressing down on the sensor. The second layer is used as a spacer for the two sensing elements in the device, allowing an ultra-high sensitivity to the initial touch, allowing the device to be used as a switch. The manual fabrication process using a pencil-drawn approach could lead to the variability of the dimensions of the sensing elements. To better control the size and thickness of graphite layers, we recommend that a precisely controlled XY stage can be implemented.

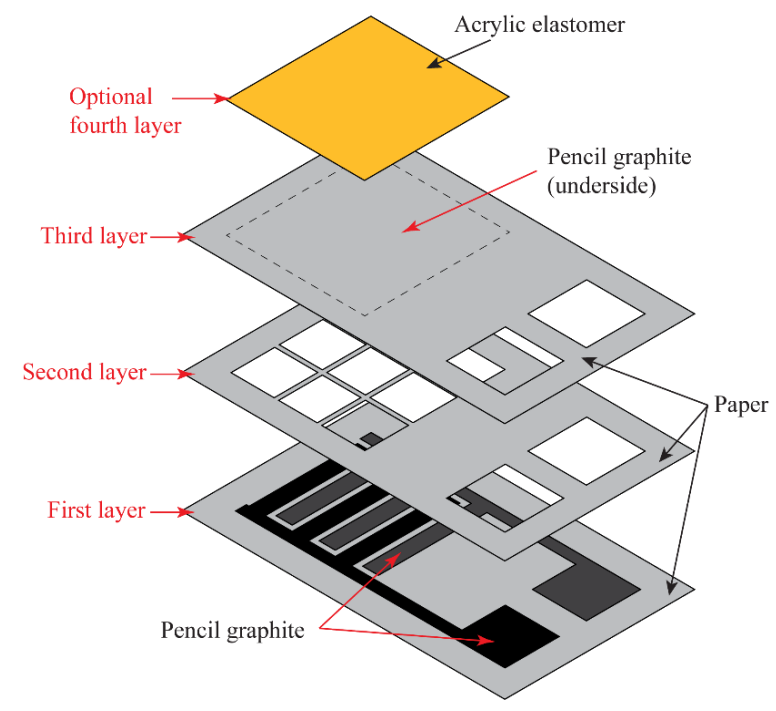

Figure 3. Assembly of the sensor.

\section{Results and Discussion}

\subsection{Material Properties}

The deposition of graphite on a porous paper substrate can be seen in Figure 4a. Three main peaks were observed in the Raman spectroscopy, presented in Figure 4b, at the wavenumbers of 1350, 1580 , and $2725 \mathrm{~cm}^{-1}$, respectively corresponding to the $\mathrm{D}, \mathrm{G}$, and $2 \mathrm{D}$ bands of the graphite material. The intensity of the G-band was much larger than that of the D-band, which was indicative of the material's high quality [35].
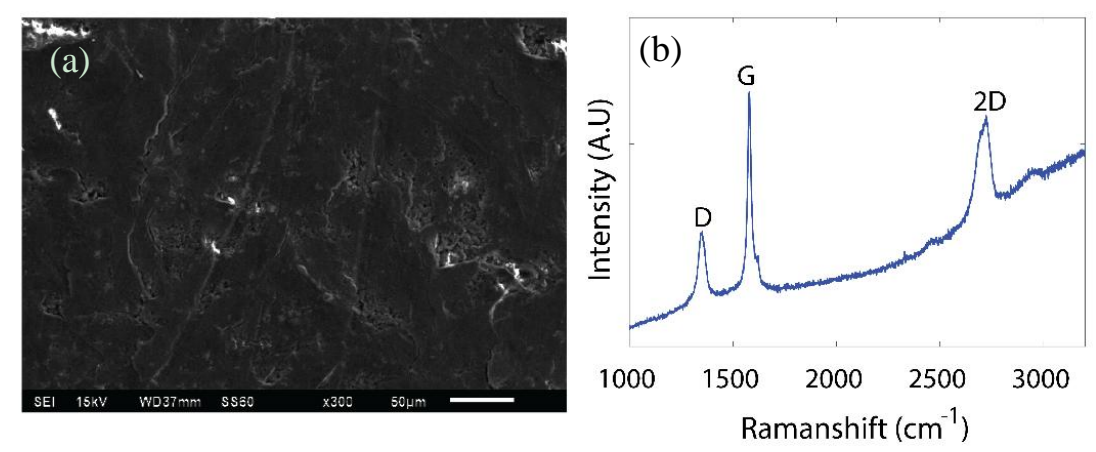

Figure 4. (a) Scanning Electron Microscopy (SEM) image of GoP, (b) Raman spectrum of GoP. 


\subsection{Switching}

A simple voltage divider circuit was implemented with a constant voltage source (Bench Power Supply, E3631A) and a Keysight Oscilloscope (MSO-X 3104A), for measurement. Schematic configuration for this experiment can be seen in Figure 5a. Pressure impulses were applied to the sensor by repeatedly tapping down on it gently, with a single index finger. It can be seen in Figure $5 \mathrm{~b}$ that the sensor has a steep increase in conductivity, under the applied low pressure. At a low-pressure range, the sensor functions as a switch, where the OFF stage (i.e., no touch) is approximately $0 \mathrm{~V}$ and the ON stage is a much higher level of approximately $2.3 \mathrm{~V}$. The difference of the touching force is very small, compared to the level of the signal at the ON stage. In this case, the touching force is expected to generate a pressure of less than $100 \mathrm{kPa}$. Therefore, the GOP device is suitable to functions as a switch, at a low pressure (e.g., below $100 \mathrm{kPa}$ ).
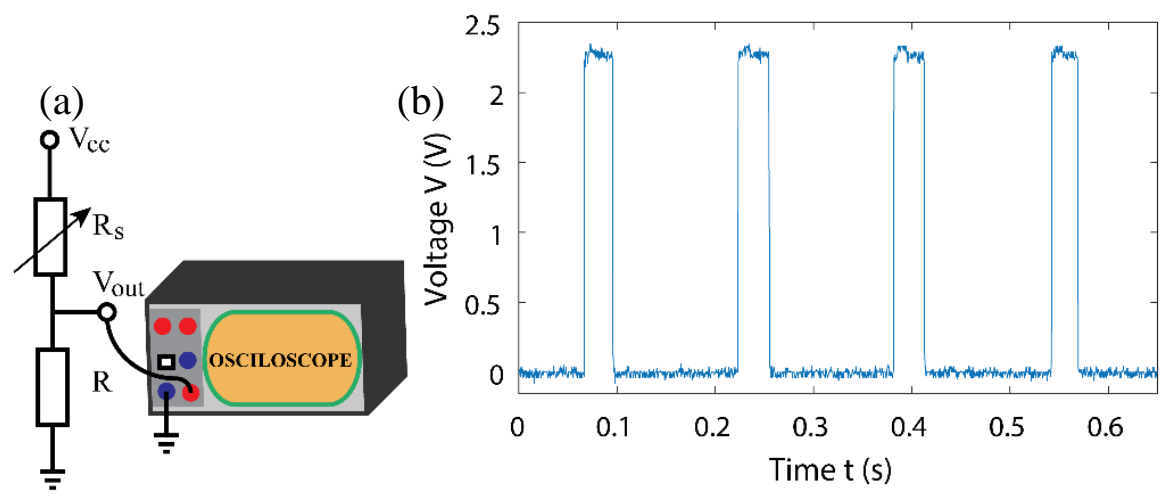

Figure 5. (a) Experimental setup $\left(\mathrm{V}_{\mathrm{cc}}=5 \mathrm{~V}\right.$ and $\left.\mathrm{R}=10 \mathrm{M} \Omega\right)$, (b) switching cycles of sensor.

\subsection{Pressure Calibration}

The sensors pressure capabilities were calibrated and tested using a Keysight USB Modular Source Measure Unit (U2722A) and an Instron Universal Testing Machine (Model 3367). Measurements were taken from both instruments, simultaneously, to obtain a reliable force/time and resistance/time values. We have measured the current-voltage (I-V) curve of the device, under different pressures, as presented in Figure 6. It was evident that all the I-V curves showed good linear characteristics, for the applied voltage, from $-1 \mathrm{~V}$ to $1 \mathrm{~V}$, indicating the good Ohmic contacts of the device. Consequently, the performance of the device was independent of the applied voltage. This also suggested that the quantum tunnelling was not dominant in our device [36,37].

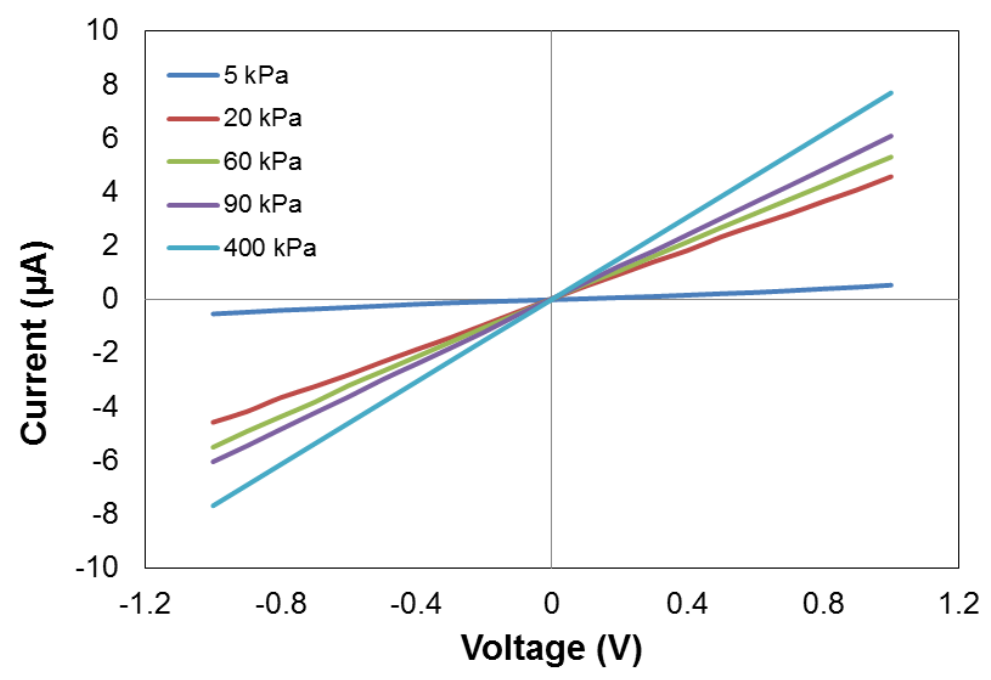

Figure 6. Current-voltage (I-V) characteristics of the sensor under different applied pressures. 
The measured force and resistance values have been aligned and combined below, in Figure 7. Pressure was applied to the sensor using a piece of precision cut $15 \times 15 \times 3 \mathrm{~mm}$ rubber (Goodyear natural rubber insertion), as such all force measurements have been appropriately converted to pressure.

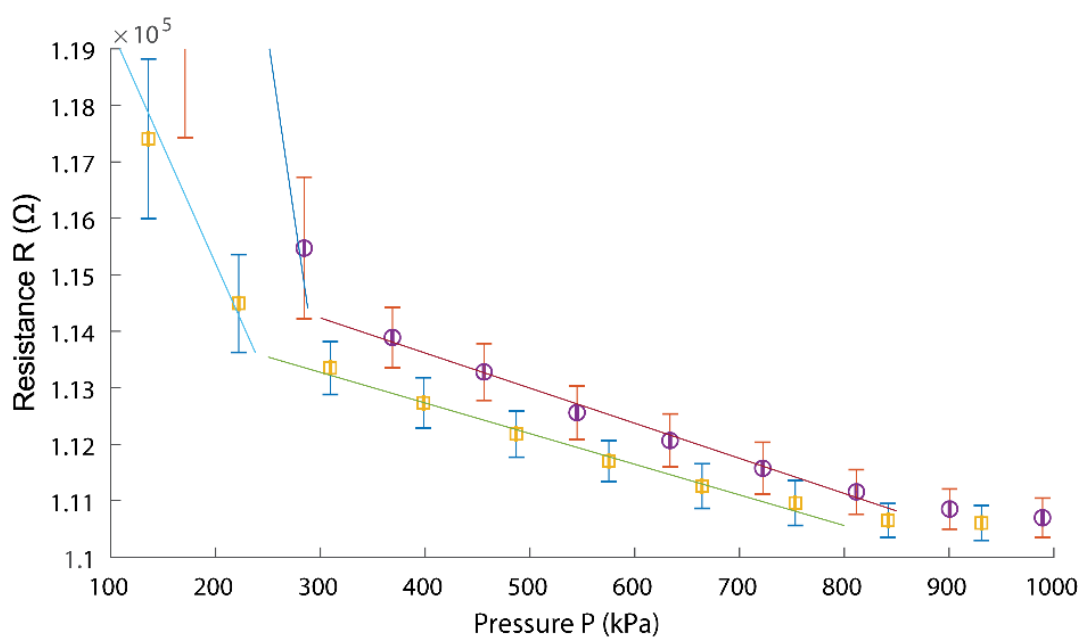

Figure 7. Calibration results where the $x-y$ standard deviation around the mean is represented as error bars, circle indicates compression, and square indicates decompression.

Based on a line of best fit, calibration showed a sensitivity of $-5.4 \times 10^{-5} \mathrm{kPa}^{-1}$ between 300 and $850 \mathrm{kPa}$, under compression, and of $-4.8 \times 10^{-5} \mathrm{kPa}^{-1}$ between 250 and $800 \mathrm{kPa}$, when released. The overall sensitivity of the sensor was, thus, referred to as approximately $-0.5 \times 10^{-4} \mathrm{kPa}^{-1}$, in its main sensing region, from $250-800 \mathrm{kPa}$. Lower pressure regions of the sensor could be characterised as $-9.1 \times 10^{-4} \mathrm{kPa}^{-1}$, between 100 and $300 \mathrm{kPa}$, under compression, and of $-3.5 \times 10^{-4} \mathrm{kPa}^{-1}$, between 100 and $250 \mathrm{kPa}$ when released. The sensitivity of our sensors was comparable to that of other pressure sensors $[25,38-40]$. In addition, the dedicated structure (very thin paper making contact window) provided an ultrafast sensor response time.

Physical connections were formed between the rough surfaces of the graphite layers, during compression. Due to the rough surface, these formed connections could stay connected, at lower pressure, while being decompressed, showing lower overall resistance in decompression. There were two distinct regions of sensitivity, the heightened sensitivity of the 100-300 kPa region could be attributed to the initial contact of the graphite-sensing areas, while the pressure range of $300-800 \mathrm{kPa}$ was no longer affected significantly, by the new contacts.

Cycle testing was performed on the sensor by applying $10-100 \mathrm{~N}$ of force $(\approx 21-210 \mathrm{kPa}$ of pressure) on the sensor in intervals of approximately $2.2 \mathrm{~s}$. Figure $8 \mathrm{a}, \mathrm{b}$ shows the change in resistance for 1000 cycles over the duration of $37.5 \mathrm{~min}$. The repeatability of the sensor over 1000 cycles, shows an excellent long-term stability. However, due to the ultra-low-cost materials and the simplicity of fabrication of the GoP, each sensor could be used in short-term service, for rapid prototyping.

The calibration results have been performed using an ohmmeter, with no reference to the influence of a source voltage to the system, as resistance measurements were taken without a source voltage. In addition, the linear current-voltage characteristics of the sensor, at different applied pressures, would suggest the independence of the sensor performance on the sourcing voltage. For future studies, the repeatability, drift, and hysteresis errors at different voltages could be further investigated to assess the overall impact of the source voltage on the device and its sensing characteristics. 


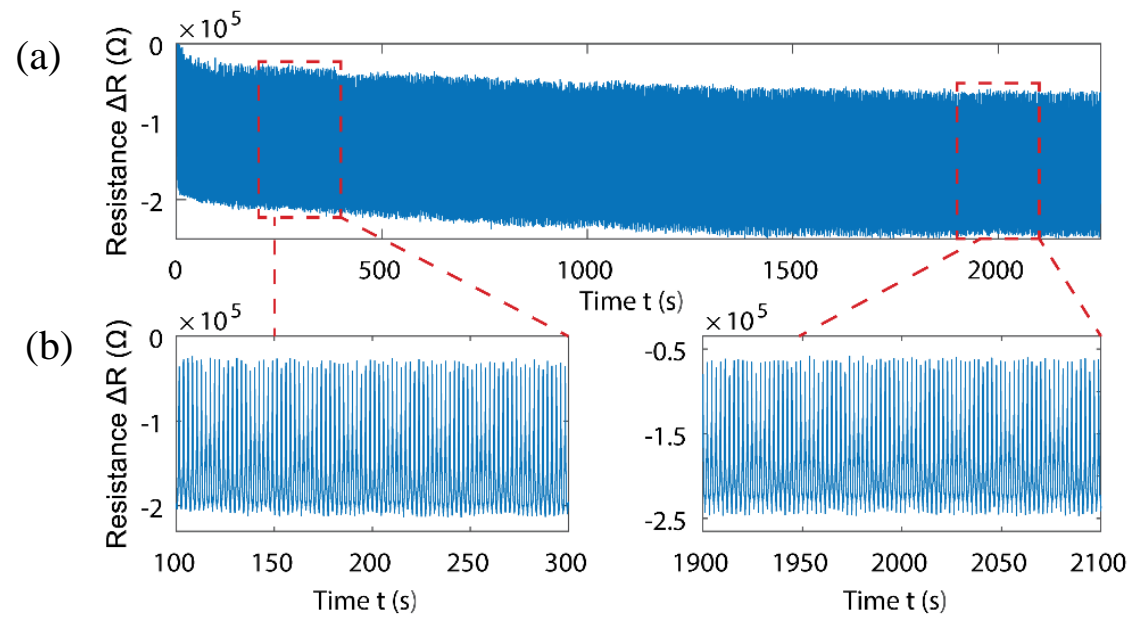

Figure 8. (a) Complete 1000-cycle test, (b) two graphs show more detailed start and end of cycle test.

\subsection{Response and Relaxation}

A simple voltage divider circuit was implemented, with a constant voltage source, to measure the response rate, performed using a Keysight Oscilloscope (MSO-X 3104A). Schematic configuration and method for this experiment was the same as used to test the sensors response to touch, as shown in Figure 5a. Fast impulses were applied to the sensor using a single index finger and response times, as fast as $50 \mu \mathrm{s}$, were observed on the oscilloscope, showing how effective each impulse could be.

However, the exported data had clipped time intervals of $0.5 \mathrm{~ms}$, effectively, limiting the calculable response, as a lot of data was emitted by the oscilloscope, when saving to the USB. Based on the recorded data, an excellent rise and fall time of $\approx 0.4 \mathrm{~ms}$ could be seen in Figure $9 \mathrm{a}, \mathrm{b}$, calculated and presented in MATLAB, using standard risetime() and falltime() functions. The reaction behaviour of the sensor included the mechanical response time and the reaction rate of the graphite. The mechanical response was the deformation of a very thin paper layer, making the contact window, and the reaction rate of graphite was fast. Altogether the sensor featured a response as fast as $40 \mu \mathrm{s}$, corresponding to a bandwidth of $2.5 \mathrm{kHz}$. This bandwidth satisfied the practical applications of robot hands, where the frequency bandwidth was typically lower than $2.5 \mathrm{kHz}$. The presented sensor was, therefore, capable of at least $\mathrm{a} \approx 2.5 \mathrm{kHz}$ switching-frequency, based on the slower response of the recorded data. This indicated the potential of using our sensor for high-speed robot hands and other high frequency applications.
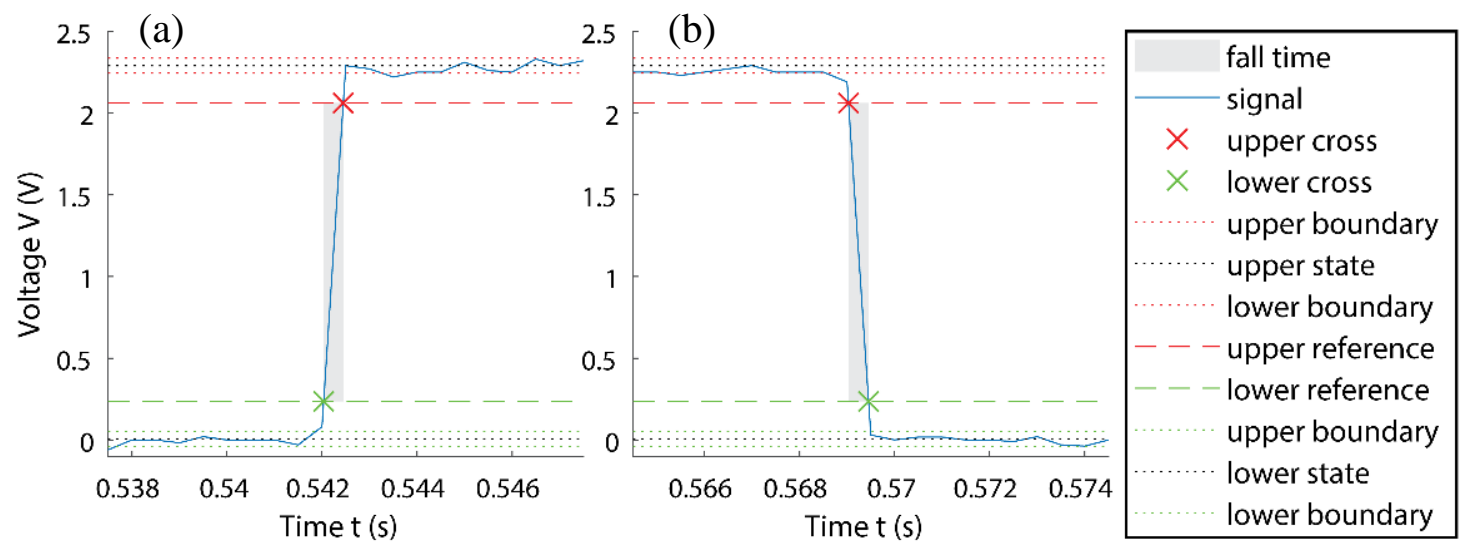

Figure 9. (a) Measured response time, (b) measured relaxation time. 


\subsection{Use in Robotic Touch Feedback Sensing}

The sensor was integrated into a Baxter robots stock parallel grippers' fingertip and used to pick up and hold a squash ball (Dunlop Pro), as shown in Figure 10. For demonstration, a simple voltage divider circuit, with a passive low-pass filter ( $50 \mathrm{~Hz}$ cut-off) was used in conjunction with a Tiva microcontroller (Texas Instruments, TM4C123GH6PM). Custom computer software was used to poll the microcontroller and record the measurement data. The grippers moving force, holding force, velocity, and position were controlled using the computer software. The ball was deformed when gripped, and then held onto, before being released slowly, in stages, as seen below in Figure 11a.

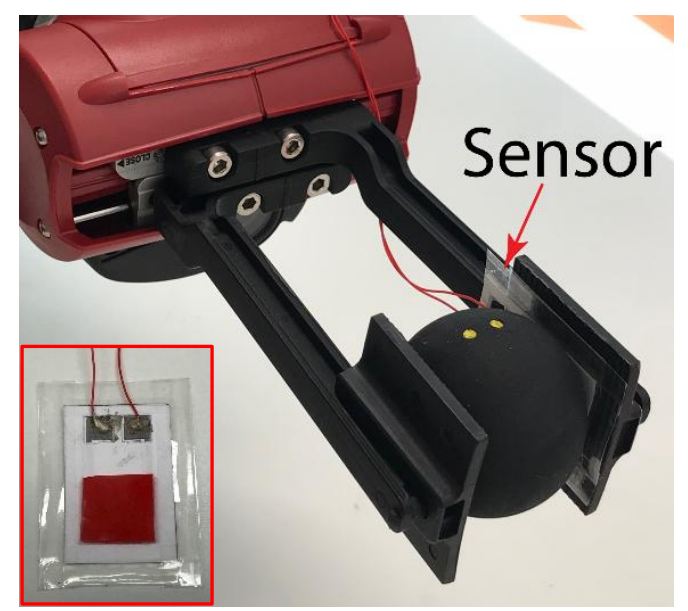

Figure 10. Sensor integrated into a robot gripper, (inset) fabricated sensor with optional fourth layer for better grip.
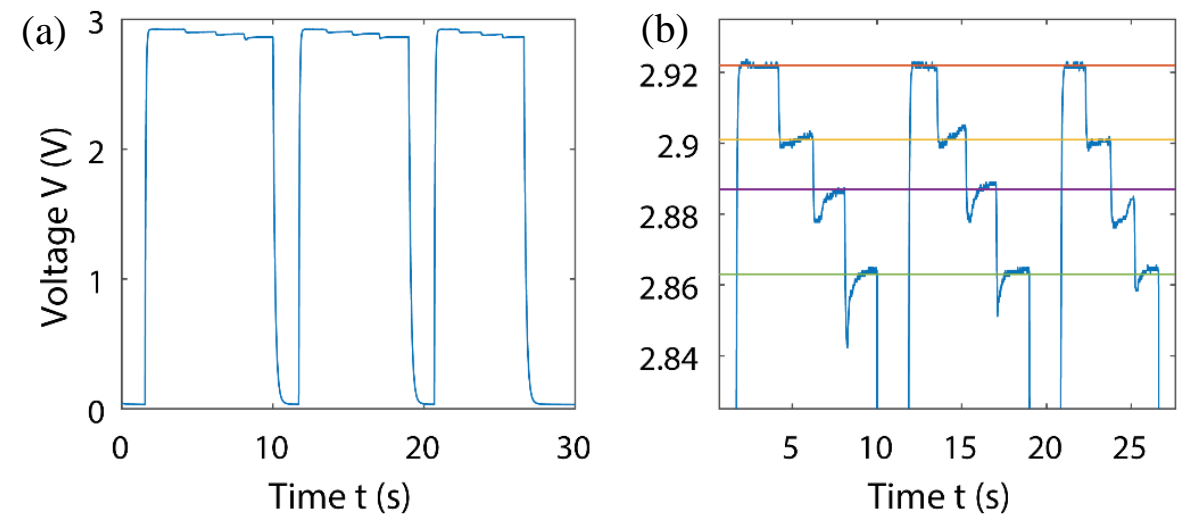

Figure 11. (a) Contact of sensor to ball, (b) close-up showing four distinct levels of applied force.

A quick rise in the output voltage was observed in Figure 11a, when the gripper first contacts the ball. Step decreases of the output voltage, detailed in Figure 11b, corresponded to the decrease in the applied pressure to the ball. The change in pressure was controlled by setting the gripping speed and modifying the desired displacement value, as the built-in controller did not allow for repeatable precision control; hence the four distinct steps were not uniform. The ball had a varying area of contact with the sensor. It was not possible to show the calibrated pressure conversions, without knowing the changing contact area of the ball, due to the performed calibration being dependent only on force, as area was non-variable. Spikes in measurements were noticed when the gripper was in motion, this could be due to the elastic properties of the ball or software implemented safety restrictions. Despite this, a fast response and clear change in signal output indicates the viability of integrating our sensor in robot grippers, providing a basis for further investigation. 
It has been shown that the first stage (Figure 11a) was for touch detection, and the second stage (Figure 11b) was for gripping force/pressure measurement. When implemented with digital control, it was possible for the control unit to compromise with the calibration curves. Further simplification of the calibration process could, therefore, be performed using these control units/microcontrollers and a set of known weights.

\section{Conclusions}

We successfully fabricated an ultra-low-cost, biodegradable, and fast response multi-purpose resistive pressure sensor. A rudimentary and effective fabrication process has been presented without the use of any solvent-based materials. The sensor showed a fast response time of $0.4 \mathrm{~ms}$ and a sensitivity of $-5 \% / \mathrm{Pa}$, in the range of $300-800 \mathrm{kPa}$. The sensor was capable of high-performance, as a switch for human touch sensing as well as a pressure sensor for robotic tactile feedback. Our sensor is a versatile, resistive, pressure sensor, capable of detecting touch motion in near real-time, demonstrating a strong feasibility of using this sensor for tactile sensing, touch displays, and wearable applications. Due to the sensor's ultra-low-cost and rapid prototyping method with standard household tools, it is possible that the sensor can be used in institutes, such as in education centres, where more advanced facilities or funding are not available.

Author Contributions: Conceptualization, J.F.-W., T.D., H.-P.P., and D.V.D.; Methodology, J.F.-W., T.D. and V.T.D.; Software, J.F.-W.; Writing, Review, \& Editing, All; Supervision, D.V.D. and F.Y.

Funding: This research received no external funding.

Acknowledgments: This work was performed in part at the Queensland node of the Australian National Fabrication Facility, a company established under the National Collaborative Research Infrastructure Strategy to provide nano and micro-fabrication facilities for Australia's researchers.

Conflicts of Interest: The authors declare no conflict of interest.

\section{References}

1. Chun, S.; Kim, Y.; Oh, H.S.; Bae, G.; Park, W. A Highly Sensitive Pressure Sensor Using a Double-Layered Graphene Structure for Tactile Sensing. Nanoscale 2015, 7, 11652-11659. [CrossRef] [PubMed]

2. Lv, L.; Zhang, P.; Xu, T.; Qu, L. Ultrasensitive Pressure Sensor Based on Ultralight Sparkling Graphene Block. ACS Appl. Mater. Interfaces 2017, 9, 22885-22892. [CrossRef] [PubMed]

3. Kim, K.-H.; Hong, S.K.; Jang, N.-S.; Ha, S.-H.; Lee, H.-W.; Kim, J.-M. Wearable Resistive Pressure Sensor Based on Highly Flexible Carbon Composite Conductors with Irregular Surface Morphology. ACS Appl. Mater. Interfaces 2017, 9, 17499-17507. [CrossRef] [PubMed]

4. Anderson, B.E. Comparison of Acceleration Sensors for American Football Helmet Impacts. Int. J. Instrum. Technol. 2015, 1, 282-293. [CrossRef]

5. Weiß, K.; Worn, H. The Working Principle of Resistive Tactile Sensor Cells. In Proceedings of the IEEE International Conference on Mechatronics and Automation, Niagara Falls, ON, Canada, 29 July-1 August 2005.

6. Lee, J.; Kwon, H.; Seo, J.; Shin, S.; Koo, J.H.; Pang, C.; Son, S.; Kim, J.H.; Jang, Y.H.; Kim, D.E. Conductive Fiber-Based Ultrasensitive Textile Pressure Sensor for Wearable Electronics. Adv. Mater. 2015, 27, 2433-2439. [CrossRef] [PubMed]

7. Kim, S.Y.; Park, S.; Park, H.W.; Park, D.H.; Jeong, Y.; Kim, D.H. Highly Sensitive and Multimodal All-Carbon Skin Sensors Capable of Simultaneously Detecting Tactile and Biological Stimuli. Adv. Mater. 2015, 27, 4178-4185. [CrossRef] [PubMed]

8. Dempsey, S.J.; Szablewski, M.; Atkinson, D. Tactile sensing in human-computer interfaces: The inclusion of pressure sensitivity as a third dimension of user input. Sens. Actuators A Phys. 2015, 232, 229-250. [CrossRef]

9. Stassi, S.; Cauda, V.; Canavese, G.; Pirri, C.F. Flexible tactile sensing based on piezoresistive composites: A review. Sensors 2014, 14, 5296-5332. [CrossRef] [PubMed]

10. Tiwana, M.I.; Redmond, S.J.; Lovell, N.H. A review of tactile sensing technologies with applications in biomedical engineering. Sens. Actuators A Phys. 2012, 179, 17-31. [CrossRef] 
11. Yousef, H.; Boukallel, M.; Althoefer, K. Tactile sensing for dexterous in-hand manipulation in robotics-A review. Sens. Actuators A Phys. 2011, 167, 171-187. [CrossRef]

12. Akar, O.; Akin, T.; Najafi, K. A Wireless Batch Sealed Absolute Capacitive Pressure Sensor. Sens. Actuators A Phys. 2001, 95, 29-38. [CrossRef]

13. He, Y.; Li, W.; Yang, G.; Liu, H.; Lu, J.; Zheng, T.; Li, X. A Novel Method for Fabricating Wearable, Piezoresistive, and Pressure Sensors Based on Modified-Graphite/Polyurethane Composite Films. Materials 2017, 10, 684. [CrossRef] [PubMed]

14. Lee, K.; Lee, J.; Kim, G.; Kim, Y.; Kang, S.; Cho, S.; Kim, S.; Kim, J.; Lee, W.; Kim, D. Rough-Surface-Enabled Capacitive Pressure Sensors with 3d Touch Capability. Small 2017, 13, 1700368. [CrossRef] [PubMed]

15. Woo, S.-J.; Kong, J.-H.; Kim, D.-G.; Kim, J.-M. A Thin All-Elastomeric Capacitive Pressure Sensor Array Based on Micro-Contact Printed Elastic Conductors. J. Mater. Chem. C 2014, 2, 4415-4422. [CrossRef]

16. Gong, S.; Schwalb, W.; Wang, Y.; Chen, Y.; Tang, Y.; Si, J.; Shirinzadeh, B.; Cheng, W. A Wearable and Highly Sensitive Pressure Sensor with Ultrathin Gold Nanowires. Nat. Commun. 2014, 5, 3132. [CrossRef] [PubMed]

17. Wu, Y.-H.; Liu, H.-Z.; Chen, S.; Dong, X.; Wang, P.-P.; Liu, S.; Lin, Y.; Wei, Y.; Liu, L. Channel Crack-Designed Gold@ Pu Sponge for Highly Elastic Piezoresistive Sensor with Excellent Detectability. ACS Appl. Mater. Interfaces 2017, 9, 20098-20105. [CrossRef] [PubMed]

18. Zhang, H.; Liu, N.; Shi, Y.; Liu, W.; Yue, Y.; Wang, S.; Ma, Y.; Wen, L.; Li, L.; Long, F. Piezoresistive Sensor with High Elasticity Based on 3d Hybrid Network of Sponge@ Cnts@ Ag Nps. ACS Appl. Mater. Interfaces 2016, 8, 22374-22381. [CrossRef] [PubMed]

19. Wu, X.; Han, Y.; Zhang, X.; Zhou, Z.; Lu, C. Large-Area Compliant, Low-Cost, and Versatile Pressure-Sensing Platform Based on Microcrack-Designed Carbon Black@ Polyurethane Sponge for Human-Machine Interfacing. Adv. Funct. Mater. 2016, 26, 6246-6256. [CrossRef]

20. Liu, X.; Zhu, Y.; Nomani, M.W.; Wen, X.; Hsia, T.Y.; Koley, G. A Highly Sensitive Pressure Sensor Using a Au-Patterned Polydimethylsiloxane Membrane for Biosensing Applications. J. Micromech. Microeng. 2013, 23, 025022. [CrossRef]

21. Pang, Y.; Tian, H.; Tao, L.; Li, Y.; Wang, X.; Deng, N.; Yang, Y.; Ren, T. Flexible, Highly Sensitive, and Wearable Pressure and Strain Sensors with Graphene Porous Network Structure. ACS Appl. Mater. Interfaces 2016, 8, 26458-26462. [CrossRef] [PubMed]

22. Samad, Y.A.; Li, Y.; Alhassan, S.M.; Liao, K. Novel Graphene Foam Composite with Adjustable Sensitivity for Sensor Applications. ACS Appl. Mater. Interfaces 2015, 7, 9195-9202. [CrossRef] [PubMed]

23. Yao, H.-B.; Ge, J.; Wang, C.-F.; Wang, X.; Hu, W.; Zheng, Z.-J.; Ni, Y.; Yu, S.-H. A Flexible and Highly Pressure-Sensitive Graphene-Polyurethane Sponge Based on Fractured Microstructure Design. Adv. Mater. 2013, 25, 6692-6698. [CrossRef] [PubMed]

24. Pan, L.; Chortos, A.; Yu, G.; Wang, Y.; Isaacson, S.; Allen, R.; Shi, Y.; Dauskardt, R.; Bao, Z. An Ultra-Sensitive Resistive Pressure Sensor Based on Hollow-Sphere Microstructure Induced Elasticity in Conducting Polymer Film. Nat. Commun. 2014, 5, 3002. [CrossRef] [PubMed]

25. Dinh, T.; Nguyen, T.K.; Phan, H.P.; Fastier-Wooller, J.; Tran, C.D.; Nguyen, N.T.; Dao, D.V. Electrical resistance of carbon nanotube yarns under compressive transverse pressure. IEEE Electron Device Lett. 2018, 39, 584-587. [CrossRef]

26. Russo, A.; Ahn, B.Y.; Adams, J.J.; Duoss, E.B.; Bernhard, J.T.; Lewis, J.A. Pen-on-Paper Flexible Electronics. Adv. Mater. 2011, 23, 3426-3430. [CrossRef] [PubMed]

27. Zhao, J.; He, C.; Yang, R.; Shi, Z.; Cheng, M.; Yang, W.; Xie, G.; Wang, D.; Shi, D.; Zhang, G. Ultra-Sensitive Strain Sensors Based on Piezoresistive Nanographene Films. Appl. Phys. Lett. 2012, 101, 063112. [CrossRef]

28. Kurra, N.; Dutta, D.; Kulkarni, G.U. Field Effect Transistors and Rc Filters from Pencil-Trace on Paper. Phys. Chem. Chem. Phys. 2013, 15, 8367-8372. [CrossRef] [PubMed]

29. Lin, C.-W.; ZZhao, h.; Kim, J.; Huang, J. Pencil Drawn Strain Gauges and Chemiresistors on Paper. Sci. Rep. 2014, 4, 3812. [CrossRef] [PubMed]

30. Yun, T.; Eom, S.; Lim, S. Paper-Based Capacitive Touchpad Using Home Inkjet Printer. J. Disp. Technol. 2016, 12, 1411-1416. [CrossRef]

31. Mazzeo, A.D.; Kalb, W.B.; Chan, L.; Killian, M.G.; Bloch, J.; Mazzeo, B.A.; Whitesides, G.M. Paper-Based, Capacitive Touch Pads. Adv. Mater. 2012, 24, 2850-2856. [CrossRef] [PubMed] 
32. Canavese, G.; Lombardi, M.; Stassi, S.; Pirri, C.F. Comprehensive characterization of large piezoresistive variation of Ni-PDMS composites. In Applied Mechanics and Materials; Trans Tech Publications: Zürich, Switzerland, 2012; Volume 110, pp. 1336-1344.

33. Lebosse, C.; Renaud, P.; Bayle, B.; de Mathelin, M. Modeling and evaluation of low-cost force sensors. IEEE Trans. Robot. 2011, 27, 815-822. [CrossRef]

34. Ding, S.; Han, B.; Dong, X.; Yu, X.; Ni, Y.; Zheng, Q.; Ou, J. Pressure-sensitive behaviors, mechanisms and model of field assisted quantum tunneling composites. Polymer 2017, 113, 105-118. [CrossRef]

35. Dinh, T.; Phan, H.P.; Dao, D.V.; Woodfield, P.; Qamar, A.; Nguyen, N.T. Graphite on paper as material for sensitive thermoresistive sensors. J. Mater. Chem. C 2015, 3, 8776-8779. [CrossRef]

36. Zhu, Y.; Li, J.; Cai, H.; Wu, Y.; Ding, H.; Pan, N.; Wang, X. Highly sensitive and skin-like pressure sensor based on asymmetric double-layered structures of reduced graphite oxide. Sens. Actuators B Chem. 2018, 255, 1262-1267. [CrossRef]

37. Simmons, J.G. Electric tunnel effect between dissimilar electrodes separated by a thin insulating film. J. Appl. Phys. 1963, 34, 2581-2590. [CrossRef]

38. Darlinski, G.; Böttger, U.; Waser, R.; Klauk, H.; Halik, M.; Zschieschang, U.; Schmid, G.; Dehm, C. Mechanical force sensors using organic thin-film transistors. J. Appl. Phys. 2005, 97, 093708. [CrossRef]

39. Metzger, C.; Fleisch, E.; Meyer, J.; Dansachmüller, M.; Graz, I.; Kaltenbrunner, M.; Keplinger, C.; Schwödiauer, R.; Bauer, S. Flexible-foam-based capacitive sensor arrays for object detection at low cost. Appl. Phys. Lett. 2008, 92, 013506. [CrossRef]

40. Lipomi, D.J.; Vosgueritchian, M.; Tee, B.C.; Hellstrom, S.L.; Lee, J.A.; Fox, C.H.; Bao, Z. Skin-like pressure and strain sensors based on transparent elastic films of carbon nanotubes. Nat. Nanotechnol. 2011, 6, 788. [CrossRef] [PubMed]

(C) 2018 by the authors. Licensee MDPI, Basel, Switzerland. This article is an open access article distributed under the terms and conditions of the Creative Commons Attribution (CC BY) license (http:/ / creativecommons.org/licenses/by/4.0/). 